Complementary

Medicine Research

Practice $\mid$ Methods | Perspectives

\title{
From Complementary to Integrative Medicine and Health: Do We Need a Change in Nomenclature?
}

\author{
Dieter Melchart ${ }^{a, b}$ \\ ${ }^{a}$ Competence Centre for Complementary Medicine and Naturopathy, \\ Klinikum rechts der Isar, Technische Universität München, Munich, Germany; \\ ${ }^{b}$ Institute for Complementary and Integrative Medicine, University Hospital Zurich and \\ University of Zurich, Zurich, Switzerland
}

Within the last 25 years, a strong worldwide movement driving the integration of safe and effective traditional practices and self-care techniques into mainstream health care has developed. The reason for this relates to a strong dissatisfaction with conventional medicine and its one-sided focus on high-tech interventions and pharmaceutical drugs for the management of established diseases. A more comprehensive approach to individual needs regarding health shall be provided through diagnostic and therapeutic methods by a nonconventional 'Complementary and Alternative Medicine (CAM)'. This term has been used by the National Institutes of Health (NIH), USA, for a long time. Thereby, the wording 'Complementary Medicine' was embossed internationally - also in German-speaking countries - and established as a concept using non-mainstream methods in combination with, not in place of, conventional medicine [1]. In contrast, the term 'Alternative Medicine' has become more or less uncommon in the nomenclature of this concept. The labeling 'Naturopathy' - as a German 'feature' based primarily on the Kneipp model - has never stopped being used in Germany, due to its long history. Anyhow, the German health care system and public also adopted the term 'Complementary Medicine'. In Switzerland, it has even become part of the constitutional law. The understanding of the concept goes along with the NIH definition and refers to all additional non-mainstream practices outside naturopathy.

Since 1994, charismatic persons like Andrew Weil (University of Arizona) pushed the term 'Integrative Medicine' in the USA and beyond [2-4]. Weil's vision focusses on the idea that everyone is responsible for their own health: 'It is up to you to learn how to maintain it and to protect your body's potential for self-healing as you go through life. No doctors, no treatments, no system can do this for you or force you to do it on your own' [3].

Thus, health promotion and preventive medicine have become fundamental features of 'Integrative Medicine'. Its concept encompasses all aspects of lifestyle, seeks to optimize the individual's innate healing capacity in case of illness, and emphasizes the patient's participation in maximizing personal health resources and protecting factors $[2,4]$.

This salutogenic approach is complementary to the concept of conventional medicine with its pathogenesis-oriented practice and theory. Using complementary approaches to foster health and wellness in terms of empowering people to keep themselves healthy and to address self-healing resources corresponds exactly to this salutogenic draft of 'Comple-

\section{KARGER}

() 2018 S. Karger GmbH, Freiburg

Fax +497614520714
Prof. Dr. Dieter Melchart

Competence Centre for Complementary Medicine and Naturopathy

Klinikum rechts der Isar, Technische Universität München

Kaiserstraße 9, 80801 Munich, Germany

dieter.melchart@tum.de 


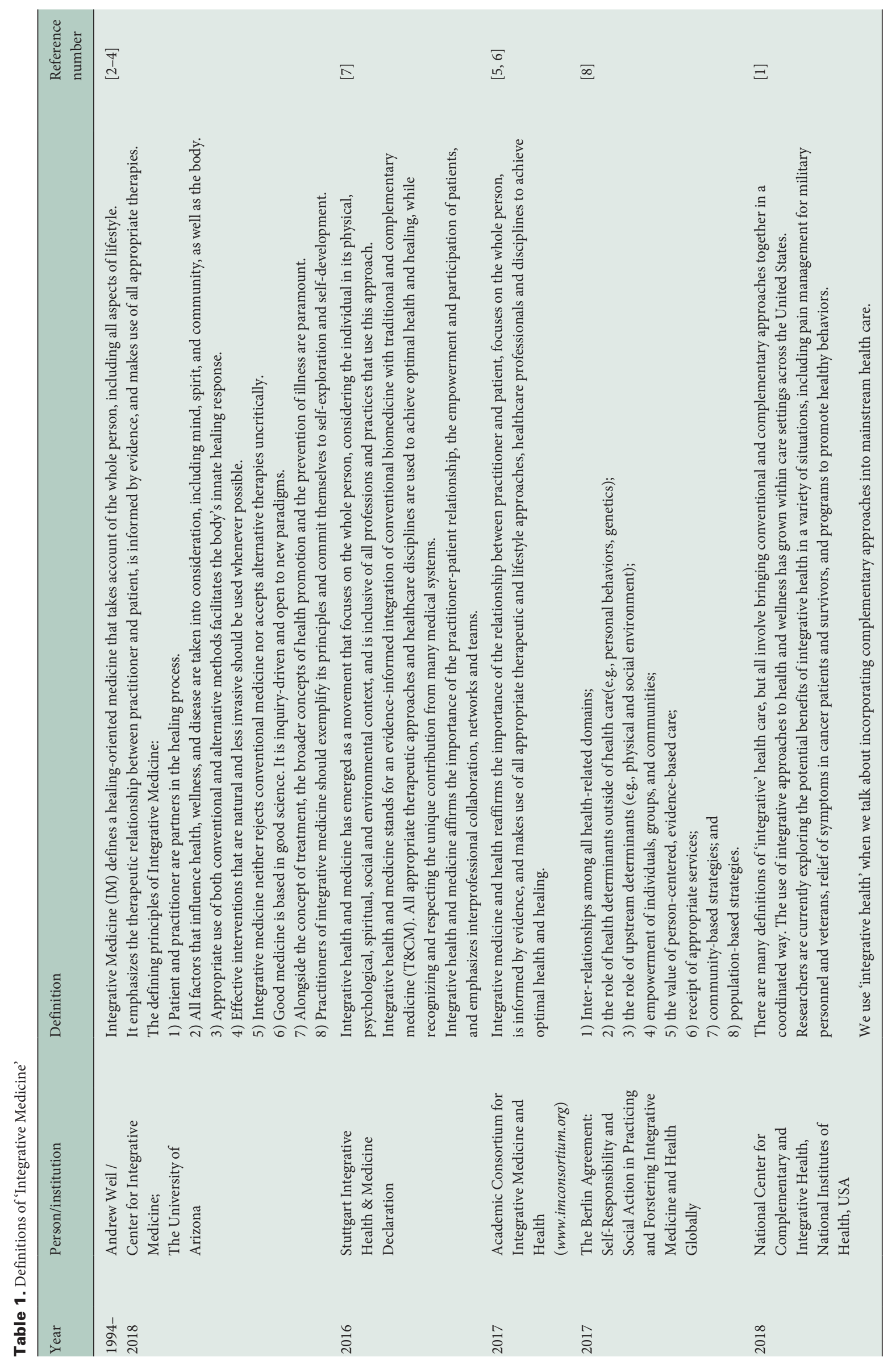


mentary Medicine'. In my opinion, there is no need for a change in nomenclature toward 'Integrative Medicine' - only to bring out the idea of salutogenic orientation. 'Integrative Medicine' has become a common term in care settings, particularly across the USA; however, this does not apply to German-speaking countries. Furthermore, there are many definitions of 'Integrative Medicine', and, moreover, the term is subject to transformation (Integrative Health) $[1,2,5,6]$. The same is true for 'Complementary Medicine' (Complementary Health) [1].

During the last couple of years, individual researchers, working groups, and institutions, like the National Center for Complementary and Integrative Health $(\mathrm{NCCIH})$ in the USA, have created their own definitions (table 1) [1-8]. Are all these activities and declarations necessary to express a worldwide movement towards more holisms and health-oriented perspectives? Is it a calling for intensified collaborative research and effective health care strategies focusing on pro-active functions in medical systems, including societies and environment? Probably everyone would agree with purpose and contents of the statements mentioned above - but is this not a current trend of many other disciplines, anyway? Different terms like 'Self-Responsibility', 'Person-Centeredness' [9], 'Comprehensive Care', 'Personalized Health Care' [10], 'Preventive Health Care', 'Individualized Medicine', 'Value-Based Health Care' [11], etc. embrace the same transformation taking place in medicine and health care. I doubt if it is reasonable to constrain all these different streams under the umbrella of 'Integrative Health'.

From a medical point of view, it is not really constructive to try to widen the concept from medicine to health by merely changing the nomenclature. In fact, there is an urgent need for a paradigm shift: from a re-active medical system to a pro-active one, with a broader access to people's living environments and working places (additionally supported by professional health coaches), in order to enable everyone to live healthier and to act more self-responsibly.

A health care system that fixates too much on pathology rather than health is neither ethically justifiable nor reasonable and forces physicians to wait until patients show symptoms of illness. Each year, millions of people die of preventable causes [12]. To remedy this situation, we do need numerous professional 'person-centered self-management education approaches' [13]. This might be the only way to avoid risk factors, to restore protective factors, and thereby - to effectively minimize disease occurrence and maximize health.

Andrew Weil's original concept of an 'Integrative Medicine' pointed out a clear commitment for making use of both conventional and 'Complementary Medicine' [2, 3]. This coincides with 'Complementary Medicine' bringing together conventional and complementary approaches. Here again: Why 'integrative' instead of 'complementary'? The NCCIH tries to make a difference by summing up that 'Integrative Medicine' brings the use of complementary and conventional approaches together in a coordinated way [1]. Does this not - simply - state the objective of proving safety and usefulness of 'Complementary Medicine' in a rigorously scientific way? Complementary Medicine Research follows the same maxim and mission to generate strong scientific evidence; thus, there is no need for a different name. From my point of view, the term 'Complementary Medicine' is not antiquated and should be kept - in science and in public.

Personally, I appreciate the ongoing debate concerning the terms 'Integrative' and 'Complementary Medicine'. However, this discussion should be conducted in an academic setting with a scientific audience. Most of the existing interpretations of 'Integrative Medicine and Health' (table 1) are too long, too complex, and thus hard to convey to patients, health care givers, and the public (at least in German-speaking countries). It might be more constructive, and convincing to our colleagues in research, to work together on the salutogenic theory, to optimize adherence through better educational support systems, and to produce resilient data on longterm effects of individual health management programs.

\section{Disclosure Statement}

Dr. Melchart has nothing to disclose.

\section{References}

1 National Center for Complementary and Integrative Health, U.S. Department of Health and Human Science, National Institutes of Health: Complementary, Alternative, or Integrative Health: What's In a Name? https://nccih.nih.gov/health/integrative-health (last accessed March 4, 2018).

2 Arizona Center for Integrative Medicine: What is Integrative Medicine? https://integrativemedicine.arizona. edu/about/definition.html (last accessed March 2, 2018)

3 Weil A: Testimony of Andrew Weil, M.D.: Before the Committee on Health, Education, Labor, \& Pensions United States Senate. Integrative Medicine: A Vital Part of the New Health Care System. February 26, 2009; www.help.senate.gov/imo/media/doc/Weil.pdf (last accessed March 2, 2018).

4 Snyderman R, Weil AT: Integrative medicine: bringing medicine back to its roots. Arch Intern Med 2002;162: 395-397.
5 Witt C, Chiaramonte D, Berman S, et al: Defining health in a comprehensive context: a new definition of integrative health. Am J Prev Med 2017;53:134-137.

6 Academic Consortium for Integrative Medicine and Health: Introduction. http://imconsortium.org/about/ about-us.cfm, 2018 (last accessed March 4, 2018).

7 Stuttgart Integrative Health \& Medicine Declaration. www.change.org/p/stuttgart-integrative-health-medicine-declaration (last accessed March 4, 2018).

8 The Berlin Agreement: Self-Responsibility and Social Action in Practicing and Fostering Integrative Medicine and Health Globally. www.ecim-iccmr.org/fileadmin/ ecim-iccmr/editors/documents/Berlin_Agreement_on_ Self-Responsibility_160417.pdf (last accessed March 4, 2018).
9 Thiel M, Längler A, Schwermer M, et al: Person-centeredness in integrative health care and integrative medical education. Complement Med Res 2017;24 (suppl 1):10-21.

10 Heusser P: The concept of 'Integrative and Personalized Health Care'. Complement Med Res 2017;24(suppl 1):1-2.

11 Bae JM: Value-based medicine: concepts and application. Epidemiol Health 2015;37:e2015014.

12 World Health Organization: The top 10 causes of death. www.who.int/mediacentre/factsheets/fs310/en/ (last accessed March 5, 2018).

13 Varming AR, Torenholt R, Helms Andersen T, et al: Targeting 'hardly reached' people with chronic illness: a feasibility study of a person-centered self-management education approach. Patient Prefer Adherence 2018;12:275-289. 